\title{
Fighting self-control failure: overcoming ego depletion by increasing self-awareness
}

Citation for published version (APA):

Alberts, H. J. E. M., Martijn, C., \& de Vries, N. K. (2011). Fighting self-control failure: overcoming ego depletion by increasing self-awareness. Journal of Experimental Social Psychology, 47(1), 58-62.

https://doi.org/10.1016/j.jesp.2010.08.004

Document status and date:

Published: 01/01/2011

DOI:

10.1016/j.jesp.2010.08.004

Document Version:

Publisher's PDF, also known as Version of record

Document license:

Taverne

Please check the document version of this publication:

- A submitted manuscript is the version of the article upon submission and before peer-review. There can be important differences between the submitted version and the official published version of record.

People interested in the research are advised to contact the author for the final version of the publication, or visit the DOI to the publisher's website.

- The final author version and the galley proof are versions of the publication after peer review.

- The final published version features the final layout of the paper including the volume, issue and page numbers.

Link to publication

\footnotetext{
General rights rights.

- You may freely distribute the URL identifying the publication in the public portal. please follow below link for the End User Agreement:

www.umlib.nl/taverne-license

Take down policy

If you believe that this document breaches copyright please contact us at:

repository@maastrichtuniversity.nl

providing details and we will investigate your claim.
}

Copyright and moral rights for the publications made accessible in the public portal are retained by the authors and/or other copyright owners and it is a condition of accessing publications that users recognise and abide by the legal requirements associated with these

- Users may download and print one copy of any publication from the public portal for the purpose of private study or research.

- You may not further distribute the material or use it for any profit-making activity or commercial gain

If the publication is distributed under the terms of Article $25 \mathrm{fa}$ of the Dutch Copyright Act, indicated by the "Taverne" license above, 


\title{
Fighting self-control failure: Overcoming ego depletion by increasing self-awareness
}

\author{
Hugo J.E.M. Alberts ${ }^{\mathrm{a}, *}$, Carolien Martijn ${ }^{\mathrm{a}}$, Nanne K. de Vries ${ }^{\mathrm{b}}$ \\ a Department of Clinical and Psychological Science, Maastricht University, P.O. Box 616, 6200 MD, Maastricht, The Netherlands \\ b Department of Health Education and Promotion, CAPHRI School for Public Health and Primary Care, Maastricht University, The Netherlands
}

\section{A R T I C L E I N F O}

\section{Article history:}

Received 22 September 2009

Revised 2 August 2010

Available online 14 August 2010

\section{Keywords:}

Self-control

Ego depletion

Self-awareness

\begin{abstract}
A B S T R A C T
According to the limited strength model (Muraven, Tice \& Baumeister, 1998), exerting self-control causes ego depletion: a depletion of cognitive resources resulting in poorer performance on later self-control tasks. Previous studies have demonstrated a positive effect of self-awareness on self-control performance. The present study examined whether the occurrence of ego depletion can be circumvented by increasing selfawareness. Initially depleted participants who received a neutral prime exhibited the classic ego depletion pattern: their performance on a subsequent physical self-control task decreased significantly. In contrast, no decrease in performance was observed for depleted participants who were exposed to a self-awareness prime. The latter group performed equally well compared to low depleted participants.
\end{abstract}

(c) 2010 Elsevier Inc. All rights reserved.
Knowing what is best for you does not always lead to behavior that is congruent with this knowledge. Terms such as "weakness of will" and "lack of self-control" have been used by modern philosophers and psychologists to explain this phenomenon (Elster, 1979). Failure of self-control is often accompanied by negative consequences: widespread problems like obesitas, drug addiction and violence reflect people's inability to control their food intake, cravings and aggressive impulses. According to the limited strength model, failure of selfcontrol emerges as a consequence of limited resources (Muraven \& Baumeister, 2000; Muraven, Tice, \& Baumeister, 1998). Resources used for an initial self-control attempt are no longer available for later attempts, resulting in decreased self-control performance. This phenomenon is labeled ego depletion and has been demonstrated in a wide range of studies. These studies have used different manipulations of self-control (e.g. thought suppression, emotion regulation, impulse control, deliberate decision making and memory tasks) and have indeed shown that when people repeatedly exert self-control within a relatively short period of time, performance on a subsequent act of self-control is likely to decrease (see for an overview, Hagger, Wood, Stiff, \& Chatzisarantis, 2010; Schmeichel \& Baumeister, 2004).

An important question is whether regulatory failure due to ego depletion can be circumvented. The present article will address this question by investigating the potential of attentional processes to overcome ego depletion. More specifically, the present contribution addresses the impact of self-focused attention or self-awareness on regulatory performance and ego depletion.

\footnotetext{
* Corresponding author.

E-mail address: h.alberts@maastrichtuniversity.nl (H.J.E.M. Alberts).
}

\section{Self-awareness}

Previous research has consistently demonstrated a unidirectional link between self-focused attention and self-control. For instance, a study by Beaman, Klentz, Diener, and Svanum (1979) showed that children were less likely to eat more than the allowed amount of candy when their self-awareness was raised by seating them in front of a mirror. Macrae, Bodenhausen, and Milne (1998) found that a heightened self-focus enhanced spontaneous suppression of social stereotypes. Highly self-aware participants were better able to exert cognitive inhibition by producing less stereotypic descriptions compared to control participants (see also Carver \& Scheier, 1981; Monteith, 1993). In sum, self-awareness increases self-control performance.

An explanation for the positive effects of self-awareness on selfcontrol is provided by the cybernetic model of self-regulation by Carver and Scheier (1981). According to this model, self-regulation is a broad, regulatory cycle of comparing the self against a relevant standard, operating on the self to reduce a possible discrepancy, testing again and continuing the process until a test reveals that the standard has been reached, whereupon the person exits the circle (test, operate, test, and exit (TOTE), cf. Carver \& Scheier, 1981). Selfawareness has been linked with the testing phase of the above described cycle, in which a person compares the present state against a relevant standard. According to Duval and Wicklund (1972), selfawareness increases the salience of an internalized, social and/or situational standard. As a result, people are more inclined to adjust or regulate their behavior to meet this standard, causing them to enter the operate phase in order to carry out the intended behavior. In other words, self-focused attention leads to a state of self-evaluation that motivates people to regulate their behavior. 


\section{Motivational intensity theory}

Although both original self-awareness theory (Duval \& Wicklund, 1972) and the cybernetic model of self-regulation by Carver and Scheier (1981) can explain why directing attention to the self enhances regulatory performance, they do not provide more insight in the relation between self-focused attention and cognitive resources. A theoretical framework that does address this relation is motivational intensity theory (Brehm \& Self, 1989; Brehm, Wright, Solomon, Silka, \& Greenberg, 1983). According to this view, resources are mobilized proportional to the experienced task difficulty as long as success is possible and worthwhile. This implies that people will invest resources unless (1) difficulty levels are beyond their ability or (2) difficulty levels require more resources than justified by the importance of success. It follows that an increase in the importance of success should justify mobilization of resources for relatively high difficulty levels. Consistent with this reasoning, Wright and Kirby (2001) introduced the term ability differences to refer to differences in performance capacity at a given moment. They state that "... ability at a given moment is determined by multiple factors, including genetics, training and energy level in the relevant performance system" (p. 264). When people suffer from low abilities, the difficulty level of a challenge will be experienced as higher compared to when abilities are high. Thus, compared to people with high ability, people with low ability due to low energy levels (e.g. ego depletion) are expected to be less persistent on high difficulty levels. However, in this view, increasing the importance of success (and thus increasing motivation) should compensate for this effect.

Indeed, some studies have demonstrated that by increasing people's motivation to perform well on a task, a decline in regulatory performance due to ego depletion can be circumvented. For instance, Muraven and Slessareva (2003) showed that initially depleted individuals persevered longer at a later self-control task if they were led to believe that their persistence would be beneficial to others or to themselves. Depleted participants, who were not motivated, lowered their persistence and thus showed ego depletion. In a similar vein, a recent study by Alberts, Martijn, Greb, Merckelbach, and De Vries (2007), investigated the impact of unconscious motivation and demonstrated that depleted participants who were primed with persistence outperformed depleted participants who were exposed to a neutral prime.

\section{The present study}

The aim of the present study was to test the effect of self-focused attention on regulatory performance when people's resources are depleted. According to Duval and Wicklund (1972), self-awareness causes people to adjust or regulate their behavior in order to meet a salient standard. When people regulate their behavior (i.e. strive to reach a certain goal), this standard involves successful achievement. Because self-awareness thus increases the importance of successful performance, motivational intensity theory predicts that self-awareness increases motivation and therefore justifies the mobilization of resources (see also Gendolla, Richter, \& Silvia, 2008). Hence, when people who are low in resources due to previous self-control attempts are exposed to a self-focus induction, they are expected to perform relatively well on a subsequent self-control task. In other words, high levels of self-awareness are hypothesized to prevent regulatory failure due to ego depletion.

The first part of the current study aimed to manipulate the level of depletion. In order to induce a high level of depletion, half of the participants exerted high self-control in a calculation task that required attention control (cf. Alberts et al., 2007). The other half received a version of the calculation task that did not require attention control, and thus was expected to cause a low level of depletion. The second part of the study intended to manipulate self-awareness. In order to induce self-awareness, participants were primed with sentences related to the self by means of a scrambled sentence task (SST, Srull \& Wyer, 1979; see also Araya, Akrami, Ekehammar, \& Hedlund, 2002; Alberts et al., 2007). We chose for an SST because it is an implicit priming technique that minimizes demand characteristics or other self-presentational concerns (Bargh \& Chartrand, 2000). Finally, self-control performance was measured by means of a physical stamina task adapted from Muraven et al. (1998) and consisted of squeezing a handgrip. Differences in performance at the first and second physical stamina measure formed the main dependent variable.

\section{Method}

\section{Design and participants}

Eighty undergraduates (64 women and 16 men) of Maastricht University were randomly assigned to a 2 (Depletion: low vs. high) $\times 2$ (Self-awareness: low vs. high) between-subjects design. Participants were individually tested in 30 min sessions and received a monetary reward for their participation. In order to minimize experimenter effects, a standardized protocol was used throughout the whole experimental procedure. The experiment was approved by the standing ethical committee of our faculty.

\section{Procedure}

The experiment was presented as a series of unrelated tasks that tested participants' cognitive and physical abilities. After signing a consent form, participants filled out a first mood scale, the Brief Mood Inspection scale (Mayer \& Gaschke, 1988). Next, all participants performed a first physical stamina task. Physical stamina tasks proved to be a successful measure of self-control in prior research (see for example Muraven et al., 1998, Study 1; Ciarocco, Sommer, \& Baumeister, 2001, Study 2). We used a handgrip task that any person can perform. However, because squeezing a handgrip becomes fatiguing and even a little painful after a short period of time the person feels the urge to stop squeezing. Overcoming this fatigue and overriding the urge to quit, requires self-control. In order to control for individual differences in physical strength, handgrip performance was measured twice; at the beginning and at the end of the experiment. The experimenter asked participants to place a handgrip in their dominant hand and inserted a coin between the two handles as the participant squeezed them together. Participants were instructed to squeeze the handgrip as long as possible. The moment the participant relaxed his or her grip, the coin fell out. The experimenter started a stopwatch at the moment he placed the coin between the handles and stopped timing when the coin fell out.

Next, level of depletion was induced through the attention control task (Alberts et al., 2007). During eight minutes, participants were asked to solve difficult calculations while they were auditively distracted during the task. Because participants had to pay attention to the calculations and needed to override their impulse to listen to the interfering noise this task required self-control. A low level of depletion was induced by a version of the task in which relatively easy calculations were presented and no interfering auditive stimuli were present. Because participants could perform the (relative easy) calculations without having to control their attention by ignoring the interfering stimuli, this task was expected to require considerably less self-control. Similar manipulations of attention control have been used to elicit depletion in previous studies of self-regulatory resources (see for instance Schmeichel, Vohs, \& Baumeister, 2003; Faber \& Vohs, 2004). After finishing the calculations, participants indicated their mood again.

Subsequently, participants completed a so-called "verbal ability task". In fact, this was a scrambled sentence task (SST). Participants in 
the self-awareness conditions were asked to unscramble 25 scrambled sentences that started with "I" (e.g. "I buy some bread"). Priming of self-related personal pronouns has been successfully used as a method to induce self-awareness in previous research (Wiekens \& Stapel, 2008). Participants in the control conditions received 25 neutral scrambled sentences in which no self-relevant pro-verbs were present (e.g. "Henk buys some bread"). The only difference between the content of these sentences and the content of the self-awareness version of the task was the replacement of "I" with first names (not their own name).

After completing the SST, participants squeezed the handgrip for the second time, following the same procedure as for the first handgrip measurement. Finally, participants indicated their mood once more and were asked to write down what they thought the experiment was about. Participants were debriefed and thanked.

\section{Dependent measures}

\section{Mood}

In order to test whether participants differed in their mood before they started with the experiment they completed the Brief Mood Introspection Scale (BMIS, Mayer \& Gaschke, 1988) (Cronbach's $\alpha=.92$ ). The BMIS consists of 16 adjectives, tapping eight mood states (happy, loving, calm, energetic, anxious, angry, tired and sad) with 2 adjectives each. Participants were instructed to rate "How well each adjective or phrase describes your present mood" using 5-point Likert scales with the endpoints 1 (definitely do not feel) and 5 (definitely feel). In addition, to check whether manipulations led to mood differences between groups, participants were asked to rate their mood again directly after the depletion manipulation and after the second handgrip performance.

\section{Manipulation check}

Participants were asked to indicate how boring, difficult and unpleasant they had experienced the calculation task. Responses were made on a 5 -point scale ranging from 1 (strongly disagree) to 5 (strongly agree).

\section{Physical performance}

Using a stopwatch, time (in seconds) was measured that participants squeezed the handgrip.

\section{Results}

Self-control performance was represented by the difference in handgrip time at the first and the second measurement. Four participants had deviant scores on the difference score of the two handgrip tasks $(z>2)$ and were recognized as outliers. Hence, analyses described below included the data of the remaining 76 participants. ${ }^{1}$

\section{Self-control performance}

A 2 (Depletion) $\times 2$ (Self-awareness) ANCOVA of the second measure of the handgrip time with the first handgrip time as covariate, revealed a significant covariate, $F(1,71)=144.49, p<.001, \eta^{2}=.67$. $^{2}$ Moreover, a significant main effect for level of depletion was found, $F(1,71)=4.37$, $p<.05, \eta^{2}=.058$, indicating the standard ego depletion effect. Participants who solved difficult calculations (high depletion) performed worse at the second handgrip measure than participants who received easy

\footnotetext{
${ }^{1}$ Including the four outliers in the analysis did not lead to a different pattern of results.

${ }^{2} \mathrm{~A}$ test of the homogeneity of regression slopes explored the parallelism of regression hyperplanes and tested the assumption that the relation between covariate and dependent variable does not vary over conditions. The absence of a significant effect, $F(3,68)=.73, p=.54$ demonstrated that the assumption of homogeneity of regression slopes was tenable.
}

calculations (low depletion). No significant main effect was found for type of priming, $F(1,71)=2.09, p=.15, \eta^{2}=.029$. More importantly, the predicted interaction of depletion level and type of priming was found, $F(1,71)=13.0, p<.001, \eta^{2}=.16$. In order to further explore this interaction effect, pre-planned pairwise comparisons were used to compare self-control performance among the four groups. First, we tested the effect of the self-awareness manipulation within the high depletion conditions (high depletion-self-awareness prime vs. high depletion-neutral prime). ANCOVA confirmed our prediction and revealed that depleted participants who were exposed to the selfawareness manipulation performed significantly better than depleted participants who did not receive any self-awareness manipulation, $F(1,36)=5.93, p=.01, \eta^{2}=.16$. Next, we compared performance between both self-awareness conditions (low depletion-self-awareness prime vs. high depletion-self-awareness prime). This time, a trend was found, $F(1,35)=3.72, \mathrm{p}=.08, \eta^{2}=.09$. Although falling short of significance, this finding does suggest that when both low and high depleted participants were exposed to the self-awareness induction, the latter benefitted the most from the induction and outperformed the first group. Means are summarized in Table 1.

\section{Manipulation checks}

As far as can be inferred from the description of the study given in their own words in the final questionnaire, none of the participants realized the true purpose of the experiment. In general, participants considered "the link between mood and physical power" as the main goal of the experiment. Participants' evaluation of the calculation task was analyzed using one-way ANOVA with type of calculation task (distraction versus no distraction) as the independent variable and ratings of difficulty, unpleasantness and boredom as dependent variables. The distraction calculation task was rated as relatively more difficult than the no distraction calculation task, $F(1,74)=$ 24.97, $p<.01, \eta^{2}=.25(m=3.13, S D=.97$ vs. $m=2.26, S D=.72$ resp.). Also, participants rated the distraction calculation task as more unpleasant than the no distraction calculation task, $F(1,74)=14.63$, $p=.02, \eta^{2}=.16$ ( $m=3.00, S D=.19$ vs. $m=2.05, S D=.99$ resp.). A marginally significant effect was found for boredom; participants perceived the distraction calculation task as more boring $(m=2.97$, $S D=1.05)$ than the no distraction calculation task $(m=2.5$, $S D=1.03), F(1,74)=3.92, p=.051, \eta^{2}=.05$.

In order to assess the effectiveness of the ego depletion manipulation, we analyzed performance on the second task in the neutral priming conditions. The evidence suggests that the depletion manipulation was effective: performance on the second task in the high depletion condition was worse than performance on the second task in the low depletion condition, $F(1,37)=19.69, p<.001 \eta^{2}=.35$. This was the case, even when performance on the first task was entered as a covariate, $F(1,36)=17.42, p<.001 \eta^{2}=.33$.

Table 1

Means and standard deviations of participants' performance at the two physical selfcontrol measurements.

\begin{tabular}{llllll}
\hline \multicolumn{1}{c}{ Condition } & \multicolumn{2}{c}{ Time 1} & & \multicolumn{2}{c}{ Time 2} \\
\cline { 2 - 3 } \cline { 6 - 6 } & $M$ & & & & \\
& & & & & $S D$ \\
\hline High depletion & & & & & \\
$\quad$ Neutral prime $(n=19)$ & 61.55 & 29.82 & & 62.64 & 3.89 \\
$\quad$ Self-awareness $(n=19)$ & 72.20 & 42.36 & & 82.69 & 3.80 \\
$\quad$ Low depletion & & & & \\
$\quad$ Neutral prime $(n=20)$ & 76.98 & 20.31 & & 84.42 & 3.70 \\
$\quad$ Self-awareness $(n=18)$ & 91.02 & 26.52 & & 75.16 & 4.02 \\
\hline
\end{tabular}

Note. Numbers under Time 1 represent mean times that participants squeezed the handgrip, in seconds. Numbers under Time 2 are adjusted for handgrip performance at Time 1. 
Mood

One-way ANOVA with condition as independent variable and scores on the BMIS taken at the beginning of the experiment as dependent variable, revealed that there were no pre-experiment mood differences among subjects in the different conditions of the experiment, $F(3,72)<1.0$. Moreover, in order to investigate whether the depletion manipulation caused differences in mood, we analyzed scores on the second mood measurement. It was found that solving easy or difficult calculations did not result in a mood difference, $F(1,73)<1.0$, $n s$. This makes it unlikely that differences in physical self-control measurements among the three conditions can be attributed to a mood effect. In addition, depleted participants who were exposed to the priming manipulation did not report different scores on the last mood questionnaire (taken after the second physical measurement) compared to depleted participants who did not receive this prime, $F$ ( 1 , $36)<1$. Likewise, priming did not affect mood of low depleted participants, $F(1,36)<1$. Furthermore, changes in mood were analyzed by comparing the difference between the second and the first mood measurement. ANOVA did not result in any significant main or interaction effects (all $p$ 's $>.25$ ). This absence of changes indicates that participants did not experience a change in mood during the course of the experiment.

\section{Discussion}

The present investigation addressed the impact of self-awareness on regulatory performance under conditions of ego depletion. It was expected that by increasing depleted people's self-awareness, regulatory failure due to limited resources can be circumvented. In line with these expectations, the data demonstrated that when depleted participants are exposed to a self-awareness manipulation, they outperform depleted participants who do not receive this manipulation. In addition, performance of low depleted participants was not influenced by the self-awareness induction, suggesting that our priming manipulation was mainly beneficial when resources were low. Similar findings were obtained in a study by Alberts et al. (2007); Study 2), where it was found that priming motivation only increased performance of depleted participants. Likewise, Muraven and Slessareva (2003) found no difference in self-control performance for high depleted and low depleted individuals who were exposed to an explicit motivation manipulation. Muraven and Slessareva suggested that depleted individuals may be more responsive to manipulations that increase motivation compared to low depleted individuals. Alternatively, these findings reflect a ceiling effect with regard to the amount of effort participants are willing to invest in certain selfcontrol tasks. Clearly, this issue warrants future research.

The current findings extend previous research on ways to overcome regulatory failure due to ego depletion and identify selffocused attention as an additional factor that contributes to regulatory success when cognitive resources are low. As described earlier, a possible mechanism that may underlie the impact of self-awareness on resource mobilization may be that the control enhancing effect of self-awareness is determined by its potential to increase the salience of standards, such as the standard to successfully enact self-control (Duval \& Wicklund, 1972). When self-aware, the salience of successful performance increases which, according to motivational intensity theory, motivates people to mobilize resources (Brehm \& Self, 1989; Brehm et al., 1983; Wright \& Kirby, 2001). An additional explanation in terms of processes may be that self-awareness prevents people to become excessively focused on the present, thereby helping them to orient their behavior toward future outcomes (Kuhl, 1982; Vohs \& Schmeichel, 2003).

The present investigation addressed the impact of self-awareness under conditions of low resources. However, at this point, the reverse causality of this relationship (the impact of low resources on self- awareness) remains unclear. The finding that self-awareness counteracts the impact of low resources is assumed to be caused by a process of self-evaluation: the salience of standards increases (Duval \& Wicklund, 1972). It may be possible that the reverse is true as well: low resources may lower self-evaluation and therefore decrease the salience of (personal) standards. Consistent with this reasoning, a study by Hofmann, Rauch, and Gawronski (2007) addressed the impact of automatic attitudes, dietary restraints standards and ego depletion on eating behavior. They found that the behavioral impact of personal standards was reduced under conditions of ego depletion. More specifically, when self-control resources were high, candy consumption was mainly predicted by participants' dietary restraint standards. However, when self-regulation resources were low, candy consumption was strongly predicted by participants' attitudes towards candies instead of dietary restraint standards. These findings support the notion that low resources impact self-evaluative processes and may provide a fruitful avenue for future research.

According to the strength model, the enactment of self-control impairs future acts of self-control. Indeed, most studies on ego depletion have illustrated a decrease in performance after initial selfcontrol efforts. The present findings demonstrate that it is possible to compensate for this temporary deficit and circumvent the occurrence of ego depletion. This effect seems to contradict the core assumptions of the strength model. However, as Muraven and Slessareva (2003) suggested, initial self-control efforts may motivate people to conserve strength. In this view, ego depletion is not a sign of complete exhaustion but rather a reflection of conservation, i.e. the tendency to spare one's resources. By increasing motivation, people are more willing to invest resources and will show less signs of ego depletion (see also Muraven, Shmueli, \& Burkley, 2006). In other words, better self-control performance due to motivation is the consequence of more willingness to drain the resource. Although this view can explain why a decrease in performance after prior self-control efforts can be circumvented, it remains unclear to what extent motivational factors can compensate for limited resources.

In sum, whereas the strength model is mainly concerned with the limits of our capacity to exert self-control, the research reported in the present article favors an approach in which more focus is placed on the flexibility and relativity of regulatory capabilities. Interestingly, the current findings can be easily explained by motivational intensity theory. Instead of considering self-control failure as an inevitable consequence of low resources, this framework addresses the impact of motivational factors as well. Such a view on self-control, in which regulatory limits are considered less static and more susceptible to adjustment, is not only more in line with human complexity and flexibility, it may also provide ways to create room for identification of additional factors and processes that improve self-control performance.

\section{Limitations}

Although previous research has repeatedly demonstrated that selfawareness increases the salience of standards (Beaman et al., 1979; Fenigstein, Scheier, \& Buss, 1975; Gibbons, 1978; Macrae et al., 1998), the present study did not directly test this assumption. Future research on the link between self-awareness and ego depletion would benefit from implementing a measure to address this increased salience. Preferably, this measure should not require conscious awareness to be effective, since the present findings suggest that self-awareness related processes can operate outside consciousness. In addition, the finding that participants were not aware of the selfcontrol enhancing effect of the priming procedure, may lie in the implicit nature of this manipulation. At this point, it remains unclear whether this unawareness remains when more explicit ways to induce self-awareness are used, like for instance a mirror or audio taped voices. 


\section{References}

Alberts, H. J. E. M., Martijn, C., Greb, J., Merckelbach, H., \& De Vries, N. K. (2007). Carrying on or giving in: The role of automatic processes in overcoming ego-depletion. British Journal of Social Psychology, 46, 383-399. doi:10.1348/014466606X130111.

Araya, T., Akrami, N., Ekehammar, B., \& Hedlund, L. E. (2002). Reducing prejudice through priming of control-related words. Experimental Psychology, 49, 222-227. doi:10.1027//1618-3169.49.3.222.

Bargh, J. A., \& Chartrand, T. L. (2000). The mind in the middle: A practical guide to priming and automaticity research. In H. T. Reis, \& C. M. Judd (Eds.), Handbook of research methods in social and personality psychology (pp. 253-285). New York, NY, US: Cambridge University Press.

Beaman, A. L., Klentz, B., Diener, E., \& Svanum, S. (1979). Self-awareness and transgression in children: Two field studies. Journal of Personality and Social Psychology, 37, 1835-1846. doi:10.1037/0022-3514.37.10.1835.

Brehm, J. W., \& Self, E. A. (1989). The intensity of motivation. Annual Review of Psychology, 40, 109-131. doi:10.1146/annurev.ps.40.020189.000545.

Brehm, J. W., Wright, R. A., Solomon, S., Silka, L., \& Greenberg, J. (1983). Perceived difficulty, energization, and the magnitude of goal valence. Journal of Experimental Social Psychology, 19, 21 - 48. doi:10.1016/0022-1031(83)90003-3.

Carver, C. S., \& Scheier, M. S. (1981). Attention and self-regulation: A control theory approach to human behavior. New York: Springer-Verlag.

Ciarocco, N. J., Sommer, K. L., \& Baumeister, R. F. (2001). Ostracism and ego depletion: The strains of silence. Personality and Social Psychology Bulletin, 27, 1156-1163. doi:10.1177/0146167201279008.

Duval, S., \& Wicklund, R. (1972). A theory of objective self awareness. Oxford: Academic Press.

Elster, J. (1979). Ulysses and the sirens: Studies in rationality and irrationality. New York: Cambridge University Press.

Faber, R. J., \& Vohs, K. D. (2004). To buy or not to buy? Self-control and self-regulatory failure in purchase behavior. In K. D. Vohs, \& R. F. Baumeister (Eds.), Handbook of self-regulation (pp. 509-524). New York: Guilford Press.

Fenigstein, A., Scheier, M. F., \& Buss, A. H. (1975). Public and private self-consciousness: Assessment and theory. Journal of Consulting and Clinical Psychology, 43, 522-527. doi:10.1037/h0076760.

Gendolla, G. H. E., Richter, M., \& Silvia, P. J. (2008). Self-focus and task difficulty effects on effort-related cardiovascular reactivity. Psychophysiology, 45, 653-662. doi: 10.1111/j.1469-8986.2008.00655.x.

Gibbons, F. X. (1978). Sexual standards and reaction to pornography: Enhancing behavioral consistency through self-focused attention. Journal of Personality and Social Psychology, 36, 976-987. doi:10.1037/0022-3514.36.9.976.

Hagger, M. S., Wood, C., Stiff, C., \& Chatzisarantis, N. L. D. (2010). Ego-depletion and the strength model of self-control: A meta-analysis. Psychological Bulletin, 136, 495-525. doi:10.1037/a0019486.

Hofmann, W., Rauch, W., \& Gawronski, B. (2007). And deplete us not into temptation: Automatic attitudes, dietary restraint, and self-regulatory resources as determi- nants of eating behavior. Journal of Experimental Social Psychology, 43, 497-504. doi:10.1016/j.jesp. 2006.05.004.

Kuhl, J. (1982). Action- vs. state-orientation as a mediator between motivation and action. In W. Hacker, W. Volpert, \& M. von Cranach (Eds.), Cognitive and motivational aspects of action. Amsterdam: North-Holland.

Macrae, C. N., Bodenhausen, G. V., \& Milne, A. B. (1998). Saying no to unwanted thoughts: Self-focus and the regulation of mental life. Journal of Personality and SocialPsychology, 74, 578-589. doi:10.1037/0022-3514.74.3.578.

Mayer, J. D., \& Gaschke, Y. N. (1988). The experience and meta-experience of mood Journal of Personality and Social Psychology, 55, 102-111. doi:10.1037/00223514.55.1.102.

Monteith, M. J. (1993). Self-regulation of prejudiced responses: Implications for progress in prejudice reduction efforts. Journal of Personality and Social Psychology, 65, 465-489. doi:10.1037/0022-3514.65.3.469.

Muraven, M., \& Baumeister, R. F. (2000). Self-regulation and depletion of limited resources: Does self-control resemble a muscle? Psychological Bulletin, 126, 247-259. doi:10.1037/0033-2909.126.2.247.

Muraven, M., Shmueli, D., \& Burkley, E. (2006). Conserving Self-Control. Strength. Journal of Personality and Social Psychology, 91, 524-537. doi:10.1037/00223514.91.3.524.

Muraven, M., \& Slessareva, E. (2003). Mechanism of self-control failure: Motivation and limited resources. Personality and Social Psychology Bulletin, 29, 894-906. doi: $10.1177 / 0146167203029007008$.

Muraven, M., Tice, D. M., \& Baumeister, R. F. (1998). Self-control as limited resource: Regulatory depletion patterns. Journal of Experimental and Social Psychology, 74 774-789. doi:10.1037/0022-3514.74.3.774.

Schmeichel, B. J., \& Baumeister, R. F. (2004). Self-regulatory strength. In R. F. Baumeister, \& K. D. Vohs (Eds.), Handbook of self-regulation: Research, theory, and applications (pp. 84-98). New York: Guilford Press.

Schmeichel, B. J., Vohs, K. D., \& Baumeister, R. F. (2003). Intellectual performance and ego depletion: Role of the self in logical reasoning and other information processing. Journal of Personality and Social Psychology, 85, 33-46. doi: 10.1037/0022-3514.85.1.33.

Srull, T. K., \& Wyer, R. S. (1979). The role of category accessibility in the interpretation of information about persons: Some determinants and implications. Journal of Personality and Social Psychology, 37, 1660-1672. doi:10.1037/0022-3514.37.10.1660.

Vohs, K. D., \& Schmeichel, B. J. (2003). Self-regulation and extended now: Controlling the self alters the subjective experience of time. Journal of Personality and Social Psychology, 85, 217-230. doi:10.1037/0022-3514.85.2.217.

Wiekens, C. J., \& Stapel, D. A. (2008). The mirror and I: When private opinions are in conflict with public norms. Journal of Experimental Social Psychology, 44, 1160-1166. doi:10.1016/j.jesp.2008.02.005.

Wright, R. A. \& Kirby, L. D. (2001). Effort determination of cardiovascular response: An integrative analysis with applications in social psychology. In M. Zanna (Ed.), Advances in experimental social psychology, 33. (pp. 255-307)San Diego: CA: Academic Press 